\title{
Subversion - The Secret Power of the Message Enlaced with the Power of the Internet and Information Technology
}

\author{
Demush Bajrami' ${ }^{1}$, Arburim Iseni2*, Anesa Topko ${ }^{3}$ \\ ${ }^{1,3}$ South East European University, North Macedonia \\ ${ }^{2}$ State University of Tetova, North Macedonia \\ *Corresponding author: arburim.iseni@unite.edu.mk
}

\begin{abstract}
Subversion! Is it the symbol of invisibility, or the symbol of the secret power? What does it represent, the ability to carry the messages secretly, or the power to change the world? What are the ideas or objects that subversion challenges? The authority, people, tradition, institution, or the whole of humanity. Can it be considered as a way to brainwash or as a means to manipulate the thoughts and opinions of people? Is the power used by people to hide their feelings from others, be subversive? Is it the point where the change and progress meet? There are a lot of numerous and different questions that can be born from just a simple word subversion. At first glance, we think it is something simple, but its true meaning has power and many methods of expression. The whole idea and aim of subversion are to overthrow the existing state or situation and bring a functioning or desired change. It also supports the idea of staying behind and moving by one's own beliefs and choices. One of the common ways that we are exposed to subversive messages is through advertisements for different products, and the messages they carry on. Because of them, our subconscious mind is made to believe and desire things that we do not truly need or want. In the age of information technology and social media, subversive messages are carried much easier and shaped based on the characteristics of target audiences. Nowadays, advertisement and political campaigns directly respond to the individual requirements of target audiences, making their messages much more acceptable and influential.
\end{abstract}

Keywords: subversion, influence, power of words, transgression, mass media, cyberattack, cybersecurity.

\section{Introduction}

The paper aims to clarify the close relationship between subversion, privacy, and security, and to demonstrate the presence of subversion in everyday life. Expansion of the information technology, that has already overcome the most optimistic 
Expectations, has created a 'warm' subversion stature. Media occupies an essential place in our daily lives.

The purpose of this paper is to reveal mechanisms such as hidden ideas, or the use of hidden power, as subversion tools, and their expression through media, films, books, and articles in the context and form that they can be considered subversive. Hence, power is seen as a more influential practice than others, being above others.

The space of exploration of the subversive role and the general tendencies of people are immanent realities. Media reality becomes a priority. Here, subversion represents the most used resources in this process, as well as access control. Internet appearance means the emergence of a global political platform, where country maps differ drastically from those on physical maps. There are no boundaries or governing rules or laws in the network, and therefore the state's jurisdiction over the Internet becomes unclear.

Often it is easy to conclude that the Internet and social media give individuals greater freedom. The massive development and use of the Internet by citizens, governmental and non-governmental sectors, political organizations, international organizations, business circles, pressure groups, and criminals and terrorist organizations have raised the aspirations of a large number of countries to regulate, control, or 'filter' network communications.

How many times did we find ourselves looking up for or buying things that, in reality, we did not need or were not necessary or useful to us? In this period of excess exposure to social media and other mediums, we are daily or even hourly exposed to subversive messages that are carried on by the articles and books we read, opinions of different newspapers, analysts, politicians, and other influential personalities. Our beliefs and thoughts for a specific topic, group of people, countries, and other things are mainly shaped by the subversive messages that we hear every day and their secret influence.

\section{Defining Subversion}

A subversion is an intentional act that provokes, opposes, or prevails the dominance of the social, cultural, or political position of "power". Subversion is the method of expressing indirectly, in a secret approach, the ideas, opinions, and concerns toward certain people or situations. It challenges, transgresses the authority, tradition, ideas, and power. Subversion uses the same power also to stay covert or unnoticed. Power seems to exercise more influence than others, being above others. Through power people can give orders, carry messages, influence, 
and make others think or act as they desire. While we get to look into the examples of the movie Avatar, two articles "Bullet in the Brain" and "This Way to the Gas, Ladies, and Gentlemen" and other means of using subversion in media and marketing, we can notice different cases of power and subversion in different levels.

"Subliminal or subversive perception is considered to be a deliberate process created by communication professionals, whereby without being aware, you tend to receive and respond to different information and instruction. Messages that may be in the form of printed words, pictures, or voice can pass through one's consciousness either way, rapidly, or ambiguously. Anything that is perceived consciously can be evaluated, discussed, or argued about and criticized, and in few cases, it can likely be rejected. Anything programmed subliminally to someone's subconscious is easily perceived and does not meet any kind of resistance. This kind of subliminal information is kept in one's brain, and it is powerful enough to influence one's judgment, manners, and points of view." (Subliminal Manipulation, 2019).

Anything heard or frequently experienced for a certain period, is obtained by one's subconscious mind and turns into a belief. People are not aware that messages that they are exposed daily through different means of communication are forming their beliefs, therefore indirectly their living styles. Whatever a person listens or watches, always gets into his or her subconscious mind. For instance, if a person watches the news, which often is negative, he or she programmes the subconscious mind with this negativity and brings it into his or her life.

\section{Expression of Subversion through Books and Articles}

Reading is something encouraged highly. Readers tend to have a vast horizon of knowledge and express themselves better. Besides, they are exposed more to new concepts and ideas, as well as the messages that are intended to be delivered. "Bullet in the brain" can be considered as a symbol of low-level kind of subversion, but with high importance and message. Here we met a person, a smart one, but at the same time a significant rebellion type. At first, we would consider this person as an individual with low self-esteem who is not fond of anything and is against everything to get attention, but the reality is quite different. This person does not walk with the flow of life or let it, or other people influence his decisions. He is the one who makes the choices in his life. This side of him is what actually represents his subversive parts. Anders - "a book critic known for the weary, elegant savagery with which he dispatched almost everything he relieved." (Wolf, 2006) In his 
writing style, one can notice a kind of resistance toward the things, phenomena that the writer, in this case, our rebel Anders, do not like or accept in his philosophy of life. He sounds like a rebellion writer, who is exercising an indirect resistance toward the things around him. If one looks closer, he/she would see that he is exercising a kind of subversion. He is not shouting to anyone but instead tells them that they are wrong. He uses the power of his pencil to tell them that they are wrong, but what is ridiculous is that they are not conscious of that. He is fooling them, he is resisting them, and he is shouting to them that they are wrong, but they do not get it personally. Indirectly he is subverting them, by settling in the position of fools, who do foolish things.

"Tragic really. If they're not chopping off the wrong leg, or bombing your ancestral village, they're closing their positions" (Wolf, 2006, p. 1), this statement is mentioned during the conversation that Anders had with a woman, while he was waiting in the bank. The problem was with the service of the bank, Anders considered it tragic, but the woman thought that it was not that tragic. Analysing the sentence, one can see that there is a kind of subversion. Anders is indirectly telling the women that they cannot see what this institution is, in reality, doing to them, and unfortunately, they will not notice it unless they are bombed or put in any similar situation.

In the part where he was describing the ceiling of the bank, he was mentioning the funny and irritating drawn figures drawn there. (Wolf, 2006) At first, they may look old and artistic, but when one looks at them carefully, it is clearly seen that they were representing the character of that institution. They cheated the eyes of people, while the bank had cheated the people themselves. With all his ironic descriptions, Anders had subverted the character of that institution. If one looks at all the conversations that Anders had with the thieves in the bank and the things that he did to them, at first sight, they can be considered as a kind of resistance. If analysed more carefully it can be seen that he is not, for instance, saying to the thieves that they are doing the wrong thing and trying to put them in an unwanted situation, or he is not merely accepting the thing that they are doing and do what he is told to do. By making fun of them, and acting as a brave person, he is indirectly making them feel less strong and important as they pretending to be and lowering their position and reputation of the strong one in front of other people. He cannot accept the fact that someone came there and tried to tell him what to do. In a way, he is saying: what do you think you are? Who are you to tell me what to do? So, in the end, he makes his own choice and does what he wants.

Even though the consequence of this choice was terrible, he saved his rebellious personality until his last moments and died staying behind his opinions and choices. All the things that he did not remember from his life express the idea that 
by forgetting them he was unconsciously subverting all these memories that might look very important, but for him, they were not as meaningful as they might seem. At first, it may seem like he was subverting them because he did not want to remember them, especially those that made him feel bad, as when he broke up with his girlfriend that he loved so much and other. On the other side, this does not mean that all of these memories were painful, maybe he was resisting in this way those that were painful, but he was surely subverting the rest because none of them was included in the priority things in his life. By subverting them, we mean that he is lowering their positions in his puzzle of life or lowering their importance, and by remembering just one thing he is showing what is indeed included in the priorities of his life. In a way or another, he is telling everyone that he is not the same as all of them, he is not satisfied with this typical cycle of life, his life may look same as theirs, but unquestionably his priorities are not the same.

Anders' story with Coyle's cousin presents best what we meant with the priorities in Anders' life. "He was a writer, a critic and all the things that had to do with writing were the priorities of his life. Even that many years had already passed from that event, and even that they were the last moments of his life, he remembered it and still felt the angriness that he could not talk at that very moment to this guy and say that he was spelling that word wrong." (Borowski, 1967, pp. 37-41). He hid that resistance for many years inside himself, and those last seconds were the time it went out from that hidden place and reminded itself as a kind of resistance that author had to make but did not make, better say as a mission that Anders had to finish but did not finish. Is not this hidden, subconscious sound subverting Anders himself, by reminding him of his uncompleted mission, that he will never have the chance to complete? Yes, it is subverting Anders and telling him he did not finish it, and how bad that he will not have any more time to complete his mission. From this story, we can see that Anders was a man who dedicated all his existence to writing and forcing his way of thinking to other people or his readers.

"This way for the gas, ladies and gentlemen" moves toward a higher level of subversion. The article describes a boy's daily experience, the things he went through during the Hitler time in the Auschwitz camp. He was not a Jew, he was from Poland, but in order for him and others to survive and have the food, they had to work. Their job was not a regular job; they had the unfortunate destiny of escorting the Jews from the trains and make them believe that nothing will happen to them. They had to clear the trains and carry the corpses of the dead people, especially children. It was not their ideal day, but for surviving, they had to do the job (Borowski, 1967, p. 1).

When the train came, and all the people were taken out, he was ordered to clean the train. In the train, there were human extremists, infants all trampled, and they were 
caring for them like chickens. He wanted to take them in the truck, where all the dead were, but one of the soldiers ordered him to hand them to women. At that moment, the soldier started lightening a cigarette, but the lightening was not working, so he examined it more carefully. (Borowski, 1967, p. 8) The soldier wants to get rid of the corps and uses power to do so. He is hiding the feeling that he cannot handle this moment and uses the power of the mind in achieving it. He is subversive because indirectly, he is hiding the fact that he does not want to see the corps, which makes him nervous and makes him look vulnerable. Thus, in order to handle this, he starts smoking and focuses on fixing the lighter. When the narrator goes towards women to give them the corpses, they start running away. It causes the soldier to start reaching to his revolver to shoot the women, but, in this very moment, a woman stands up to him and says that he does not have to shoot and takes the corpses. She says to him 'My poor boy' and smiles. It changes everything, because, in all this cruelty and pain, there is a woman going against everything. In a subversive way, she states that there are still good people, that there is still light of hope.

While a woman was subverting the situation by expressing compassion, and having hope in good people, some mothers denied their children in order to survive. When a woman went out of the train, she started walking quickly, and a girl running behind her was crying and calling "Mamma! Mamma!" (Borowski, 1967, p. 10). The soldier asked her to pick her child up, but she denied the fact that she was her child and started to run. She wanted to reach people who would have to walk. She was giving up her only child in order to live by herself. She denied the child, even though the child kept calling mamma and asked for her help. This is subversive to the law of nature, to the love a mother has for a child. They say that the love, bond of a mother for a child is so vast and powerful that the mother does everything that she can for her children, but in this case, she is subverting the idea, by putting down the law, denying the child. Beyond this, it is describing indirectly, how people are ready to do everything in order to survive by themselves. It is describing the most horrible thing a person can do, sacrificing a child. It is a higher level of subversion, which led to the killing of the mother and child by the soldiers.

Furthermore, the highest level of function of this article is that it is subversive to the whole of humanity. People are not supposed to cause such pain toward others and kill each other. This article, in an indirect way, describes all the horrible features of people; except for the women that show compassion and hope that there are still good people. Moreover, soldier brutality, war and in the meantime, mother sacrificing the daughter is leading to the idea that all humanity is built to act this way. The author himself accepts this by saying that he does not care about the Jews; he hated them because they were the reason of him being here doing all these 
things. Therefore, we can see that through the entire article, he is subverting the reality by expressing his concerns for the direction the humanity is moving.

\section{Expression of Subversion through Mass Media}

The most famous experiment with subliminal messaging in history is the one conducted by a marketing researcher and psychologist James Vicary in 1957 in a movie called Picnic. Words "Hungry? Eat popcorn" were repeated every five seconds, while "Drink Coca Cola" were projected for 0.003 seconds. That was extremely frequent and fast. Thanks to the abovementioned experiment, the sales of popcorn and Coca Cola in the New Jersey Theater increased 57.8 per cent and 18.1 per cent respectively. (Subliminal Manipulation, 2019) Following the effect of the movie, a lot of conducted scientific researches confirmed without any doubt that subliminal messaging functions. When the advertising industry and government agencies got in touch with the potential of subliminal messaging, they began to invest millions in forming and developing subliminal techniques that could be used besides marketing also in propaganda and mind control. In 1962 Vicary suddenly denied the results of the experiment and confessed that he had fabricated them. Why would someone, who made such a huge discovery, discredit himself in such a way and harm all of his dignity, reputation and reliability? As it can be noticed, he was paid and enforced to make this announcement. "As the saying goes: The greatest trick the Devil ever pulled was convincing the world he didn't exist" (Subliminal Manipulation 2019, p.4). It is the trick used to convince the world that subliminal messaging does not work. People deny the fact that a secret technology has been used on them for long periods to manipulate with their views, judgments and beliefs. Technology has invisibly altered their choices, channelled new values, and managed their motives, directing them into pathological behavioural patterns that are in the interest of specific power structures or groups. People are not ready to believe the person if that person tells them anything like that. "Yet subliminal messages are being bombarded to them continuously throughout the day, through books, movies, magazines, television, radio and music. Every major newspaper, every poster, every magazine has subliminal messages." (Subliminal Manipulation, 2019, p. 4)

"How is it possible for something that is not really noticed to affect the behavior of people in such extent? Well, if something is unnoted does not mean that it is unseen. Firstly, in this case the way that perception works should be understood. As it is known, mind is structured of two interacting parts: conscious and subconscious. The subconscious part of mind operates below the level of conscious awareness, it controls reflexes, automatic functions and handles the processing and 
storing of incoming information. Subconsciousness is able to process 20,000 bits of information simultaneously, while consciousness can deal only with $7 \pm 2$ bits of information at the same time" (Subliminal Manipulation n.d, p.5). "It is very interesting that certain words like BLOOD, DEATH, and such have the same effect in triggering the attention of people as their name." (Subliminal Manipulation, 2019, p. 6)

"'Avatar' is a magnificent and very interesting movie, but not just because of its technical wizardry. It has an inspiring message of resistance in the face of exploitation, and apparently overwhelmingly odds. The main characters of the movie, members of the Na' vi people, rise up to protect their homeland in a struggle of national liberation against a corporate empire which is seeking to destroy their way of life in order to steal their natural resources. Sounds like a very familiar message, right? The colonizers consider themselves more civilized due to their technological superiority but what comes across most strongly is their emotional immaturity and inhumanity, expressed in their lack of empathy for others and the environment, in which their own needs and interests are the only consideration." (Yaqoob, 2019)

"The parallels with the 'war on terror', corporate greed, and environmental destruction will not be lost on many of those watching the movie. The film is also unusual in that it portrayed the consequences of the cold unleashing of destructive power on those on the receiving end. Even more unusual for a blockbuster was that it crossed into subversive one by emotionally tracking the journey of those facing injustice such as fear, terror, hurt, pain and then resistance. The film does this without resorting to crude stereotypes, and encompasses subtlety and beauty instead, which makes it even more powerful - and worth watching again." (Yaqoob, 2019) This scenario is prevalent in our days, considering the situation in the Middle East and other similar cases.

"Another good example would be the case with the famous chocolate of Toblerone. Sometimes brands and their logos turn out to be so familiar, that people are not ready to realize or notice the real significance and message behind the design. In fact, every logo represents a thought and belief, and is designed based on a set of intentions that embody the brand and becomes their hallmark." (MDirector, 2019).

"In Toblerone's case, its logo firstly leads the attention to the mountains of Alps, which is the origin of this chocolate. Through the image of the mountain it is aimed to bring the attention of people or consumers to the Cervino Mountain, the fifth highest peak in the Alps." (MDirector, 2019) "If looked carefully at the image of the mountain it is seen that there is a hidden silhouette: A bear. Bear is the animal 
or symbol that creates a connection amid Toblerone with Berna, the town of the chocolates' origin." (MDirector, 2019)

An excellent example of the subversive messages carried in the era of information technology would also be political campaigns. In the age of social media, the political beliefs of people are also highly influenced. The availability of databases of each of the users in social media platforms has made it much easier for political actors to carry their messages and ensure their acceptability. Nowadays, each political campaign uses a presentation format whose emotional appeal has been optimized for the target audience, relying on predictive analytics and individualized political messaging.

\section{Subversion in Cyber Attack and Security}

Cyber Security and Internet privacy require setting the challenges and offering solutions to significant problems that are evident today in the field of Information and Communication Technologies. Now, it is time to consider the knowledge, contribution and experiences of experts of cybersecurity and privacy regarding the transformation and adaptation of our lifestyle in the digital world, which is increasingly posing a highly challenging problem for the field of security and privacy. Since today it is not discussed whether there is cyber-attack or not, but instead when will it happen, Jonathan Homer, with the U.S. Department of Homeland Security's National Cybersecurity and Communications Integration Center says: "Most cyber-attacks require multiple weaknesses or vulnerabilities of some form in order to be able to reach the final objective of the attacker. One of the biggest weaknesses of any corporate network is the human element." (VOA, 2019)

"System or cybernetic subversion is defined as 'the covert and methodical undermining of internal and external controls over a system lifetime to allow unauthorized or undetected access to system resources and/or information."' (Myers, 1980) Subversive artifice can occur at any phase of the system lifecycle with different consequences on the effectiveness and the ability to avoid detection."

Because subversion is a likely mode of cyber-attack, it is necessary to examine the elements needed to ensure the successful use of subversion. These elements mainly are means, motive and opportunity. For the first element, means, the adversary should have the intellectual capacity and the vital resources to perceive and develop system subversion. A motive is always present. Adversaries' main goal is, in most cases, to damage opponents. For instance, "Russia is trying to "cause disruption" and destruction of democracy in Britain, France and other Western 
states, using propaganda, subversion, and cyber-attacks", said Britain's National Security Adviser Mark Sedwill during a parliamentary session (Insajderi.com, 2019). This case is a current challenge in Europe, and it is risking the stability and democracy of the continent. Besides, opportunity asks for the adversary to have access to the targeted system at some point during its lifecycle. To implant an artifice successfully, the adversary should not have only access to the system but must not be detected too.

Subversion, as a threat, presents a significant risk bearing in mind adversaries engaged in a wide range of information warfare activities. Recent security incidents, especially in the political arena, as well as historical records of subversion, prove that the threat is real. Investigation of the requirements for carrying out subversion specifies that it is feasible in the context of the build-out of contemporary commodity systems. Alleviation of the subversion threat indicates the most fundamental aspect of the security problem: proving the absence of a malevolent artifice. An analysis of methods that could be applied to alleviate the subversion demonstrates that the application of an effective security engineering technique combined with formal methods provides a feasible approach to the alleviation of the subversion threat. With the current evidence for the existence of the threat, it can be said that those that are responsible for critical national and military systems would be negligent in failing to deal with this threat.

\section{Conclusion}

In conclusion, through the analysis of the articles above we got a clearer understanding of subversion and power concepts, and their development through different levels and means. We could see that subversion and power are part of the human's character, reflected as a way to express themselves, resist and enforce changes. Subversion and power are not always used to make changes, but in many cases, they are also used as mirrors to reflect the negative situation and misleading games that are happening behind the scene. They are also injected to us daily by being exposed to different advertisements, articles and other information that are carried to us through different mediums. Each of the information has a different and unique message to carry on to its target audiences and subconsciously turn them to their beliefs.

\section{References}

Borowski, T. (1967). This way for the gas, ladies and gentlemen: and other stories. Cape. Insajderi.com. (2019). Insajderi.com. Available from: https://insajderi.com/: https://insajderi.com/rusia-perpiqet-ta-shkaterroje-demokracine-perendimore/ 
MDirector. (2019). MDirector 11 examples of advertising and marketing with subliminal messages. Available from: messages: https://www.mdirector.com

/en/digital-marketing/examples-marketing-subliminal-messages.html

Myers, P. A. (1980). Subversion: the neglected aspect of computer security. NAVAL POSTGRADUATE SCHOOL MONTEREY CA.

Subliminal Manipulation. (2019, 4 7). Available from: http:// subliminal

manipulation.blogspot.com/blogspot.com/

VOA. (2019). More Dependence on Internet Leads to More Cyberattacks Worldwide. Available from: https://www.voanews.com/a/dependence-on-internet-leads-to-morecyberattacks/4001728.html

Wolff, T. (2013). Bullet in the Brain. Blackstone Audio, Incorporated.

Yaqoob, S. (2019). Avatar's Subversive Message. Available from: www.salmayaqoob.com: http://www.salmayaqoob.com/2010/02/avatars-subversive-message.html 